\title{
COMBINED STRATEGIC AND TACTICAL NEGOTIATION METHODOLOGY FOR RESOLVING COMPLEX BROWNFIELD CONFLICTS
}

\author{
Keith W. Hipel* \\ Department of Systems Design Engineering \\ University of Waterloo \\ Waterloo - Ontario, Canada \\ kwhipel@engmail.uwaterloo.ca \\ Tarek Hegazy \\ Department of Civil Engineering \\ University of Waterloo \\ Waterloo - Ontario, Canada \\ Saied Yousefi \\ Department of Systems Design Engineering \\ University of Waterloo \\ Waterloo - Ontario, Canada \\ * Corresponding author / autor para quem as correspondências devem ser encaminhadas \\ Recebido em 02/2009; aceito em 01/2010 após 1 revisão \\ Received February 2009; accepted January 2010 after one revision
}

\begin{abstract}
An innovative negotiation methodology for strategic and tactical decision making is proposed for resolving conflicts in brownfield redevelopment. At the strategic level, the Graph Model for Conflict Resolution is systematically employed for determining a potential overall agreement, or set of resolutions, that is politically possible given the competing interests of the decision makers involved in a brownfield redevelopment project. At the tactical level, a possible strategic solution can be studied in depth using utility theory to determine trade-offs or concessions needed to reach a mutually acceptable detailed solution. Also, the proposed negotiation methodology can take into account the attitudes of negotiators and investigates the impact of the negotiators' attitudes on the outcome of negotiations at both levels of negotiation. The design of a negotiation decision support system is put forward to allow the proposed negotiation methodology to be conveniently applied to actual disputes.
\end{abstract}

Keywords: soft systems thinking; brownfield redevelopment; infrastructure negotiation. 


\section{Introduction}

According to the US Department of Housing and Urban Development (2007), brownfield projects refer to abandoned, idled, or under-utilized residential, industrial, and commercial sites exposed to environmental contamination. Brownfield areas include decommissioned refineries, former railway yards, old waterfronts and riverbanks, crumbling warehouses, abandoned gas stations, former dry cleaners, and other commercial properties where toxic substances may have been used or stored. Therefore, brownfield projects are often called reconstruction projects in which the land has to be cleansed and the existing buildings may have to be demolished so that new structures can be reconstructed. In Canada, it is estimated that as much as $25 \%$ of the land area in major urban centers and infrastructure projects is potentially contaminated because of previous industrial activities (Benazon, 1995).

Brownfields constitute a widespread and growing problem in both industrialized and developing countries around the world caused by the steady migration of industries out of central cities. They exist in very large numbers and pose serious environmental and health risks to people. For example, the United States is believed to have between 500,000 and 1,000,000 brownfield sites, and Germany about 362,000 (NRTEE, 2003). Canada may have up to 30,000 brownfields, including the sites of almost-forgotten industrial enterprises, such as coal gasification plants, locations where toxic substances were used or stored, and former gas stations and mining operations (De Sousa, 2001).

Costs of cleanup for these sites are unknown, but some estimates are as high as billions of Canadian dollars. Left as they are, brownfield areas can harm local economies and threaten human health and environmental quality. Moreover, if brownfield areas are left idle and unmanaged, they represent a significant loss of economic opportunity. They adversely impact a neighborhood's image and quality of life. On the other hand, redeveloped brownfields usually make effective use of existing municipal infrastructure and are strategically located along existing transportation corridors.

Due to enormous uncertainties and unexpected events connected to brownfield redevelopment, the involved parties, such as the current owner, government, and environmental groups, have to spend tremendous amounts of time in many rounds of negotiation with the hope of reaching an agreement to clean up a given contaminated site. They must analyze past and present information in order to make effective offers and counteroffers leading to a deal, such as transfer of ownership, cleanup, and redevelopment of a brownfield property.

The primary objective of this research is to investigate the growing conflicts and intensifying disputes involved in brownfield projects and propose a systematic negotiation methodology for resolving brownfield conflicts at two complementary levels: strategic and tactical. At the strategic level, the proposed methodology employs the Graph Model for Conflict Resolution (GMCR) (Fang et al., 1993) and helps negotiators find the most beneficial subset of solutions to the conflict. At the tactical level, the proposed methodology examines the most beneficial strategic decisions using utility functions to suggest specific tradeoffs for resolving conflicting issues.

Due to the ongoing global recession, there is no doubt that many nations are devoting enormous sums of money to infrastructure renewal and expansion in order to "prime" their economic engines to overcome the recession which started to envelope the globe in late 2008. Because brownfield redevelopment can be considered as an important component of infrastructure revival, the foregoing types of soft OR (operation research) tools should have 
widespread applicability as explained in this paper. Specifically, in Section 2, an overview of the benefits and challenges of brownfield redevelopment and conflicts involved in brownfield reuse are discussed. Within Section 3, the role of negotiation in engineering decision making is pointed out, while in Section 4 the Graph Model is put forward as a promising OR tool for resolving conflict. In Section 5, the proposed two-level negotiation methodology for addressing brownfield redevelopment conflicts is presented, followed by concluding remarks in Section 6.

\section{Brownfield Redevelopment}

Restoring brownfield sites brings about numerous benefits. However, brownfield redevelopment also gives rise to a host of physical and societal challenges, leading to disputes among the parties involved in the redevelopment. Such conflicts need to be resolved in an effective manner before brownfield restoration can occur. To develop a means of facilitating successful brownfield negotiation, the characteristics of the property's owner, the purchaser, and the government need to be taken into account.

\subsection{The Benefits of Brownfield Redevelopment}

The restoration of brownfield sites provides a range of economic, social, and environmental benefits to stakeholders at the national, regional, and community level (NRTEE, 2003). From an economic perspective, brownfield redevelopment has a total output multiplier of 3.8, one of the highest impacts measured in Canada (NRTEE, 2003). Other economic benefits include the development of exportable restoration technologies, provision of an expanded tax base for all levels of government, and creation of employment opportunities. These sites are often sizable parcels of land, situated near existing infrastructure, transportation routes, markets, and labor pools, thus giving competitive advantage to companies that can make use of them (PolicyLink, 2008).

From a social perspective, brownfield restoration can eliminate the health threats that toxic sites pose to a community. It can also improve the quality of life of a community. Redevelopment of brownfield sites offers an extremely important opportunity for new uses of 'eyesore' properties, such as affordable housing, shopping, health clinics, transportation, or open space (PolicyLink, 2008).

Finally, environmental benefits of brownfield restoration include restoration of environmental quality and improvement of air and water. Furthermore, encouraging the redevelopment of brownfields is an important way of "recycling" parcels of land rather than building on previously undeveloped "greenfields." Greenfield development requires new roads, new sewer lines, and other infrastructure, and contributes to sprawling development patterns. When brownfields are redeveloped, further infrastructure is unnecessary, which lessens the burden on the environment and taxpayers (PolicyLink, 2008).

\subsection{Challenges Encountered in Brownfield Redevelopment}

Although there are several benefits in redeveloping brownfield lands, the challenges encountered are also considerable. The technology for brownfield redevelopment exists, but costs are often substantial. Interest on the part of developers and lending institutions in

Pesquisa Operacional, v.30, n.2, p.281-304, Maio a Agosto de 2010 
redeveloping contaminated sites has tended to be minimal because such projects may involve high cleanup costs that limit the profit margin. Moreover, developers fear being held liable for any negative environmental effects that could be traced to the redeveloped site. On the other hand, these sites are potentially valuable because they are often located in the core sections of infrastructure areas and thus are prime candidates for urban redevelopment and renewal (Bourne, 1995; Barnett, 1995). Hence, financial considerations are an important factor when remediation strategies are selected. One common solution is installing engineered barriers and setting deed restrictions to ensure that there is time for contaminants to attenuate naturally. Costs for some remediation strategies are very sizable, which often leads to cost allocation disputes and protracted negotiations among interested parties before remediation can be carried out.

Figure 1 summarizes a list of brownfield challenges from the physical and societal systems perspectives. Brownfield restoration can benefit from a Systems Engineering approach, in which both the physical and societal systems aspects of the problem are captured in an integrative manner to achieve decisions that provide optimal benefits to stakeholders. From a physical systems viewpoint, one must be aware of the physical characteristics of a given brownfield site as well as the capabilities of remediation technologies to restore the location in both the short and long term according to desirable levels of performance. With respect to societal considerations, one must adopt approaches that take stakeholders' value systems into account and that cooperatively arrive at sensible resolutions to brownfield redevelopment, as explained in Figure 1.

\section{Physical Systems Challenges}

- Inventory of properties suspected as brownfield sites;

- Classification of brownfield sites according to a range of characteristic factors so that brownfield redevelopment projects can be better understood and prioritized;

- Characterization of available technologies for brownfield remediation; and

- Environmental risk assessment.

\section{Societal Systems Challenges}

- Identifying involved stakeholders;

- Aggregating of value systems;

- Ascertaining stakeholders' value systems;

- Determining economic incentives and other non-physical components of brownfield redevelopment;

- Evaluating alternative solutions to brownfield redevelopment based on value systems;

- Cost-benefit analysis to determine the most beneficial solution option based on the various alternative costs;

- Conflict resolution and negotiation support systems available for use by the involved decision makers to reach mutual agreement;

- Coordination of policy development and decision-making systems among different levels of government; and

- Improving the effectiveness and speed of approval for brownfield reconstruction projects.

Figure 1 - Brownfield Redevelopment Challenges. 


\subsubsection{Brownfield Conflicts and Disputes}

Resolving disputes among the involved stakeholders is one of the most important challenges that is frequently encountered in brownfield projects. Because of the environmental and health risks associated with brownfield areas, legislation requires the owners of such properties to clean up the contamination. Due to the high cost of remediation, the investors are reluctant to buy and redevelop brownfield areas (Page, 1997). Begley (1997) also noted that developers and investors are concerned about the risk of future liability. In addition, many researchers and practitioners (e.g., Bartsch et al., 1991; Griffiths, 1996) have pointed out many challenges, such as chain of title liability uncertainty, lender hesitation, time to occupancy, community support, proposed land use, condition of the local infrastructure, support of local politicians, availability of financial incentives, and number of jobs to be created. It is essential, therefore, that government representatives (e.g., municipalities) promote cooperation between owner(s) and potential investor(s) so that the parties can share the cost as well as the benefits of redeveloping brownfield sites. Because of the above challenges, many changes, surprises, and disagreements can occur during the remediation process. Such disagreements may bring the remediation to a temporary halt, resulting in delays, cost overruns, and conflicts among the parties involved.

\subsection{Alternative Dispute Resolutions}

Traditionally, unresolved conflicts and disputes involving large and complex brownfield and reconstruction projects generally result in complex construction litigation (Pinnell, 1999). Lengthy and expensive litigation processes have made construction professionals less eager to have their day in court, opting instead to resolve their disputes among themselves, as has been done for thousands of years (Glasner, 2000). In response to the increased cost and duration of litigation, the construction industry has gravitated toward Alternative Dispute Resolution (ADR) procedures (Mix, 1997). Historically, the construction industry has been seeking innovative and creative ways to resolve conflicts and disputes arising from construction projects (Henderson, 1996; Mix, 1997). Not only are the costs of court claims avoided, but there are also intangible benefits to not involving the courts, such as maintaining reputation and avoiding emotional stresses (Cheung \& Suen, 2002). Harmon (2003) has summarized the characteristics of ADR tactics.

In brownfield conflicts, like many other construction conflicts, various dispute resolution procedures are available, as shown in Figure 2, with different levels of outcome control and associated costs (Richter, 2000). For the parties involved in brownfield conflicts to resolve conflicts in a less costly and less hostile way (left side of Figure 2), negotiation is one of the more preferred choices by which parties try to reach a mutual agreement. 


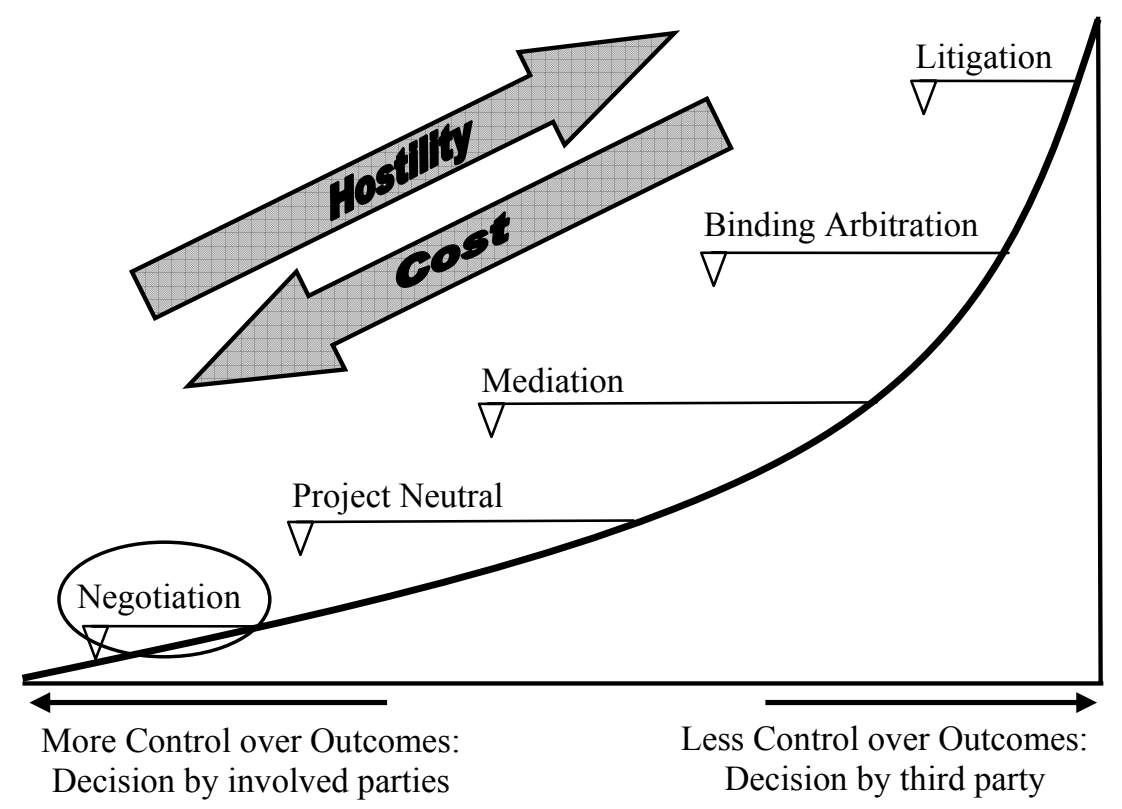

Figure 2 - Dispute Resolution Continuum, Based on Richter (2000).

\subsection{Brownfield Negotiation}

Negotiation over brownfield problems allows all parties to fairly share uncertainties and risks involved in brownfield conflicts. In brownfield negotiations, the parties present offers and counter-offers, while their objectives and interests are often hidden. As discussed by Loosemore (1999), decisions in this process involve offer-formulation and concessionmaking. Explanations, threats, inducements, incentives and other forms of communication often complement offers. Concessions are made in the goal space and typically involve reduction of the expected goal achievement levels.

Due to the high levels of risk and uncertainty involved with brownfield problems, the concerned parties often display typical behavior before and during rounds of negotiation. These brownfield negotiation characteristics are summarized in Table 1 and are explained by Yousefi et al. (2008). The negotiators' characteristics in brownfield negotiations outlined in Table 1 present a clear view of the objectives and needs of the various parties. Taking these characteristics into account is useful in determining ways to encourage the stakeholders to actively participate in the negotiation process, and is essential for the development of a practical negotiation methodology for resolving brownfield conflicts. 
Hipel, Hegazy \& Yousefi - Combined strategic and tactical negotiation methodology for resolving complex brownfield conflicts

Table 1 - Summary of Negotiation Characteristics in Brownfield Problems (Yousefi et al., 2008).

\begin{tabular}{|c|c|}
\hline Involved Parties & Characteristics \\
\hline Owner & $\begin{array}{l}\text { - Lack of the funds or the will to clean up the contaminated property } \\
\text { - Willing to share the liabilities for cleanup through negotiation } \\
\text { - Sometimes avoids officially cooperating when the owner is forced to clean up } \\
\text { the property } \\
\text { - Avoids revealing his/her/its identity } \\
\text { - Tries to understand the concerns of prospective purchaser } \\
\text { - Must account for costs of redevelopment }\end{array}$ \\
\hline Purchaser & $\begin{array}{l}\text { - Prefers to have environmental testing / certificate } \\
\text { - Takes into account the preferences and interests of the owner } \\
\text { - Very concerned about the risks of buying the property } \\
\text { - Usually one purchaser considers buying the contaminated property } \\
\text { - Must account for time and costs of redevelopment } \\
\text { - Must assume responsibilities of future contamination not caused by purchaser }\end{array}$ \\
\hline Government & $\begin{array}{l}\text { - Available resources of municipalities are the key issue to making a deal among } \\
\text { involved parties } \\
\text { - Willing to have contaminated property cleaned up and redeveloped } \\
\text { - Concerned about the justification of the resources used for brownfield } \\
\text { redevelopment } \\
\text { - Non-remedied contamination is the key future concern } \\
\text { - Tends to be more risk averse }\end{array}$ \\
\hline
\end{tabular}

\section{Negotiation in Engineering Decision Making}

Negotiation is a decision making process in which two or more parties conduct communications or conferences with a view to resolving differences between themselves (Cohen, 2002; Raiffa et al., 2002). Engineering decision making is grouped into two extreme levels: the strategic level and the tactical level, as shown in Figure 3. The flowchart on the left side of Figure 3 contains the main factors that must be considered in the selection of a suitable solution for a given engineering problem. In addition to proper engineering modeling, any alternative solution must be assessed with respect to environmental, economical and financial, and political and social feasibility (Hipel \& Fang, 2005). Appropriate techniques from systems engineering and operational research can assist with these evaluations throughout the decision-making process. The top cell on the left in Figure 3 indicates that output from all of the analyses provides information to assist decision makers in making an eventual overall decision (Hipel et al., 2007).

The right-hand portion of Figure 3 depicts the characteristics that are embodied in the hierarchical framework of the engineering decision-making process. It should be noted that as one moves from the tactical level of decision making to the strategic level, the problem changes from being highly structured and quantitative to being unstructured and qualitative. Hence, the overall problem contains both hard and soft system components. Because of these and other factors, an appropriate set of systems tools must be selected in order to investigate all relevant aspects of the systems being studied. When modeling strategic interactions among decision makers, especially at the strategic level where information tends to be unstructured and more qualitative, one can employ the Graph Model for Conflict Resolution (Fang et al., 1993). 


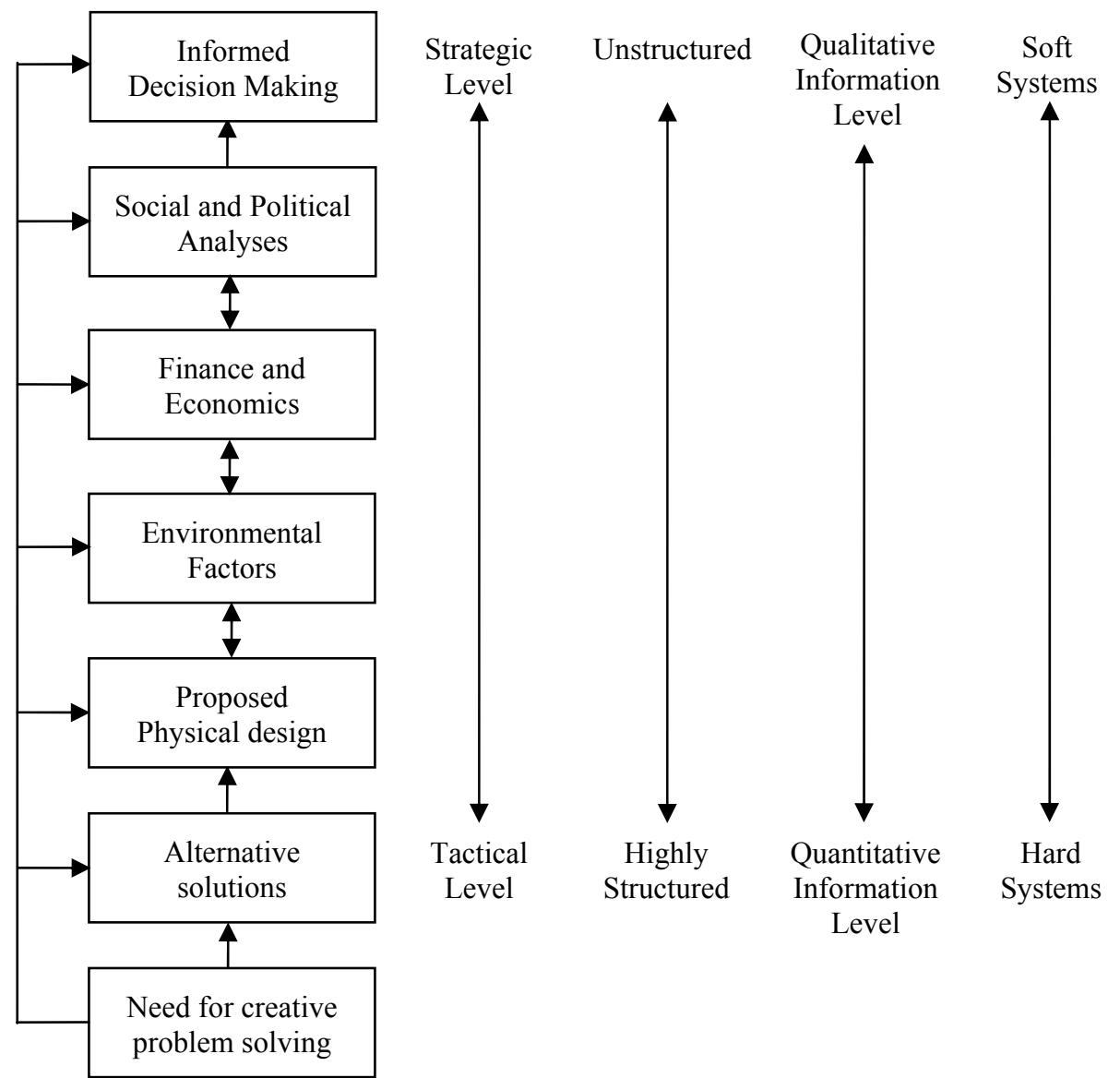

Figure 3 - Engineering Decision Making (Hipel et al., 2007).

\section{Graph Model for Conflict Resolution}

The Graph Model for Conflict Resolution (GMCR) (Fang et al., 1993) is a methodology for modeling and analyzing decision makers' interactions in a conflict in order to find stable states for all decision makers which represent feasible resolutions of the conflict. GMCR is classified as a non-quantitative approach to game theory (Hipel \& Fang, 2005). Since only relative preference information is required in the calibration of a conflict model, GMCR, which originates from conflict analysis (Fraser \& Hipel, 1984) and metagame theory (Howard, 1971), utilizes concepts and definitions from graph theory, set theory, and game theory (Von Neumann \& Morgenstern, 1944). In the Graph Model, each decision maker's possible moves from one state to other states are kept track of using a directed graph in which nodes represent states and arcs indicate state transitions controlled by the decision maker (DM). A state is a potential outcome, or scenario, of the conflict. The associated decision support system GMCR II conveniently implements GMCR (Hipel et al., 2001; Fang et al., 2003a, b). It uses the option form for conflict modeling and determines the stability of every state for each DM under a broad range of stability types. GMCR II is 
generally able to predict a variety of equilibrium information, which enhances the analyst's understanding of the conflict and results in useful advice to DMs about whether possible outcomes are strategically stable, and if so, how to reach them.

\subsection{GMCR Framework}

The systematic procedure for applying the Graph Model follows two main stages: modeling and analysis, as shown in Figure 4. In the modeling stage, the problem is structured by determining the DMs, their options or possible actions, the states, the possible state transitions controlled by each DM, and each DM's relative preferences with respect to the states. Next, in the analysis stage, the stability of each state from each DM's viewpoint is determined. The objective is to find the stable states for each DM - a state that is stable for all DMs constitutes a resolution for the conflict. The essential parts of a graph model in option form are the DMs and the options available to each DM. In general, a DM may exercise any combination of the options he or she controls to create a strategy. When every DM has selected a strategy, a state is defined.

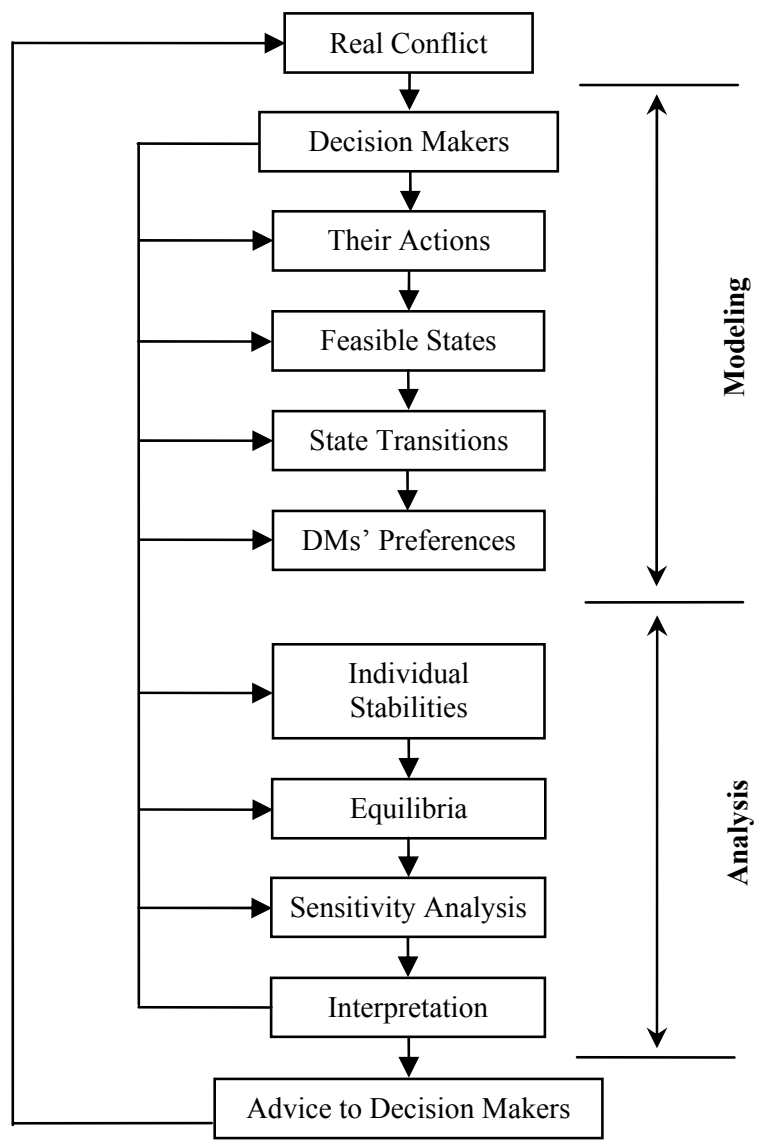

Figure 4 - Systematic Procedure for Applying GMCR (Fang et al., 1993; Hipel et al., 2001; Fang et al., 2003a,b). 


\subsection{Stability Analysis}

The stability of states for DMs is defined by various solution concepts, or stability definitions. Nash stability (Nash, 1950, 1951) reflects a DM who thinks only one step ahead. In general metarationality (GMR) (Howard, 1971) and sequential stability (SEQ) (Fraser \& Hipel, 1984), a DM thinks exactly two steps ahead in terms of a move by a given DM and countermove by an opponent, whereas in symmetric metarationality (SMR) (Howard, 1971), the DM takes into account three steps by assessing available escapes from any sanctions that may be imposed by the opponents. Disimprovement refers to the tendency of a DM to move to a less preferred state in order to reach a more preferred state eventually or to block the unilateral improvements of other DMs. In both Nash and sequential stabilities, disimprovements are never permitted, while in general and symmetric metarationality, disimprovements by the opponents for the purpose of sanctioning are allowed. Since different solution concepts may be appropriate for different DMs, states that are stable under many solution concepts are usually preferred. Thus, it is important to consider more than one kind of solution concept for each DM in order to ensure a robust prediction of the conflict resolution.

\subsection{Definitions of Solution Concepts}

A state is considered to be stable for a DM if and only if (iff) that DM is not tempted to move away from it unilaterally. A state is in equilibrium, or is a possible resolution under a particular solution concept, if all DMs find it to be stable under that solution concept. A rich variety of solution concepts and their brief descriptions are summarized in Table 2. These definitions can be easily generalized to apply to conflicts involving more than two decision makers. Mathematical definitions of these solutions within the Graph Model paradigm are furnished by Fang et al. (1993, 2003a,b). In an introductory chapter to two edited books, Hipel $(2009 a, b)$ puts the field of conflict resolution into proper perspective by pointing out contributions by authors working in areas such as Operations Research, Systems Engineering, Game Theory, Psychology, Sociology, and business, by whom articles are contained in the two books.

Table 2 - Solution Concepts Implemented in GMCR (Fang et al., 1993).

\begin{tabular}{l|l}
\hline \multicolumn{1}{c|}{ Stability Type } & \multicolumn{1}{c}{ Description } \\
\hline Nash $(\mathrm{R})$ & Focal DM (decision maker) has no unilateral improvements. \\
\hline $\begin{array}{l}\text { General Metarationality } \\
(\text { GMR })\end{array}$ & $\begin{array}{l}\text { Focal DM's unilateral improvements are all sanctioned by } \\
\text { subsequent unilateral moves by other DMs. }\end{array}$ \\
\hline $\begin{array}{l}\text { Symmetric Metarationality } \\
(\text { SMR })\end{array}$ & $\begin{array}{l}\text { Focal DM's unilateral improvements are sanctioned, even after } \\
\text { responses by the focal DM. }\end{array}$ \\
\hline Sequential (SEQ) & $\begin{array}{l}\text { Focal DM's unilateral improvements are all sanctioned by } \\
\text { subsequent unilateral improvements by other DMs. }\end{array}$ \\
\hline Limited-move $\left(L_{h}\right)$ & $\begin{array}{l}\text { Focal DM prefers not to move, based on assumption that all } \\
\text { DMs act optimally over up to } h \text { state transitions. }\end{array}$ \\
\hline Non-myopic $(\mathrm{NM})$ & $\begin{array}{l}\text { Limiting case of limited move stability as the maximum number } \\
\text { of state transitions }(h) \text { increases to infinity. }\end{array}$ \\
\hline
\end{tabular}




\subsection{Sensitivity Analysis}

Sensitivity analysis is employed to make sure that uncertainty in the DMs' preferences and other model parameters as well as sudden or unforeseen events do not affect the robustness of the stability analyses. Sensitivity analysis focuses on the implications of changes in model parameters, by considering, for example, how the preferences of a DM would have to be changed in order to produce more preferable equilibria for another DM. A reasonable range of possible preferences can be analyzed in order to ascertain how equilibria are affected. If the equilibria do not change as preferences are modified, one can have greater confidence in the results of the analysis. Alternatively, when small preference changes produce dramatic equilibria changes, then the analyst must ensure that the model is as accurate and reliable as possible. The following constitutes different types of sensitivity analyses that can be carried out to determine their effects upon the strategic results:

- Systematic preference changes (Ben-Haim \& Hipel, 2002; Hipel \& Ben-Haim, 1999)

- Unknown preferences (Li et al., 2004a)

- Fuzzy preferences (Al-Mutairi et al., 2008)

- Strength of preferences (Hamouda et al., 2004, 2006; Xu et al., 2009a)

- Option modification or expansion

- Other decision makers are added to the conflict

- Coalition formation and analysis (Kilgour et al., 2001; Inohara \& Hipel, 2008a,b)

- Emotions (Obeidi et al., 2005, 2009)

- Attitudes (Yousefi et al., 2008, 2010; Inohara et al., 2007; Walker et al., 2009) (See Section 5.2)

One can also trace the possible evaluation of a dispute from a given status quo to a desirable outcome (Li et al., 2004b, 2005). Additionally, a matrix representation of graph model analyses can be used in the design of the engine of the next generation of a decision support system for the graph model (Xu et al., 2009b). In the next section, attitudes are formally incorporated into a soft systems thinking approach to negotiation at the strategic and tactical levels of decision making.

\section{Proposed Negotiation Methodology: A Soft Systems Thinking Approach}

The negotiation methodology proposed in this research represents a soft systems thinking approach which systematically incorporates the negotiators' attitudes into the modeling of the negotiation at the strategic decision analysis level as well as at the tactical level. Figure 5 displays the framework of the systematic negotiation methodology and the steps involved in developing each stage of the methodology. More details about the methodology development are provided by Yousefi et al. $(2008,2010)$. It should be mentioned that the soft systems approach has been studied by other researchers such as Checkland (1999), Eden (1988), Rosenhead \& Mingers (2001), and Friend \& Hickling (2005). 


\subsection{Application of Proposed Negotiation Methodology to a Brownfield Dispute}

The proposed negotiation framework shown in Figure 5 is used to resolve conflicts among decision makers (DMs) involved in a brownfield case study. In this application, the land of a privately owned property is contaminated, and according to the municipality's laws, the property is considered a brownfield site which needs to be redeveloped in two steps: remediation, which means that the contaminated soil must be replaced, contained, or treated; and redevelopment, which means that a new structure or physical facility is to be constructed. Due to the enormous costs, responsibilities, risks, and uncertainties involved with brownfield redevelopment, conflicts have often arisen between the current property owner and municipalities. To illustrate this conflict, a hypothetical case study is considered in which the DMs are the owner and the government.

\subsection{Strategic Level of Negotiation}

The strategic level of negotiation for the case study at hand is developed using GMCR, which was introduced in Section 4. The steps involved within the paradigm of GMCR and shown in Figure 4 are employed to find the best possible strategic solution for the owner and the government in the case study. Also, to consider the psychological aspects of the DMs in this research, the attitudes of DMs are incorporated into the proposed negotiation methodology to investigate the influence of DMs' attitudes on the outcomes of brownfield negotiations. The range of definitions for attitudes in this research follows those defined by Inohara et al. (2007, 2008), as well as by Yousefi et al. (2010) and Walker et al. (2009), and are presented as follows.

\subsubsection{Attitude Representation}

Psychological factors, such as human perception and attitudes, are certain to influence decision making. Despite the assumption of economists of the perfect rationality of people when they decide, the fact is that people often have faulty intuition about their own motives and behaviors, and they often act to bring about outcomes that they themselves judge to be bad (Kahneman \& Tversky, 2000). Psychologically, people experience internal conflict and alter their behavior when facing decision making. They often approach decisions as they would problem-solving tasks, trying to gauge the various attributes and come up with compelling arguments for choosing one option over another.

Attitude is one of the most influential psychological features of negotiation. Attitude is a learned predisposition to respond in a consistently favorable, neutral, or unfavorable manner with respect to a given object. Due to the significant impact of negotiators' attitudes on the outcome of negotiations, the attitudes of negotiators are modeled and incorporated into the proposed negotiation methodology. As such, the formal definition of attitude is presented in the following:

Formal definition of attitudes: For DMs i, $\mathrm{j} \in \mathrm{N}$, where $\mathrm{N}$ is the set of DMs, let $\mathrm{E}_{\mathrm{i}}=\{+, 0,-\}^{\mathrm{N}}$ represent the set of attitudes of DM i. An element $e_{i} \in E_{i}$ is called the attitudes of DM $i$ for which $e_{i}=\left(e_{i j}\right)$ is the list of attitudes of DM i towards DM j for each $j \in N$ where $e_{i j} \epsilon\{+, 0,-\}$. The $e_{i j}$ is referred to as the attitude of DM i to DM j where the value $e_{i j}=+, e_{i j}=0$ or $e_{i j}=-$ indicates that DM $\mathrm{i}$ has a positive, neutral, or negative attitude towards $\mathrm{DM} \mathrm{j}$, respectively. Of course, these definitions hold for situations in which there are more than two DMs. 


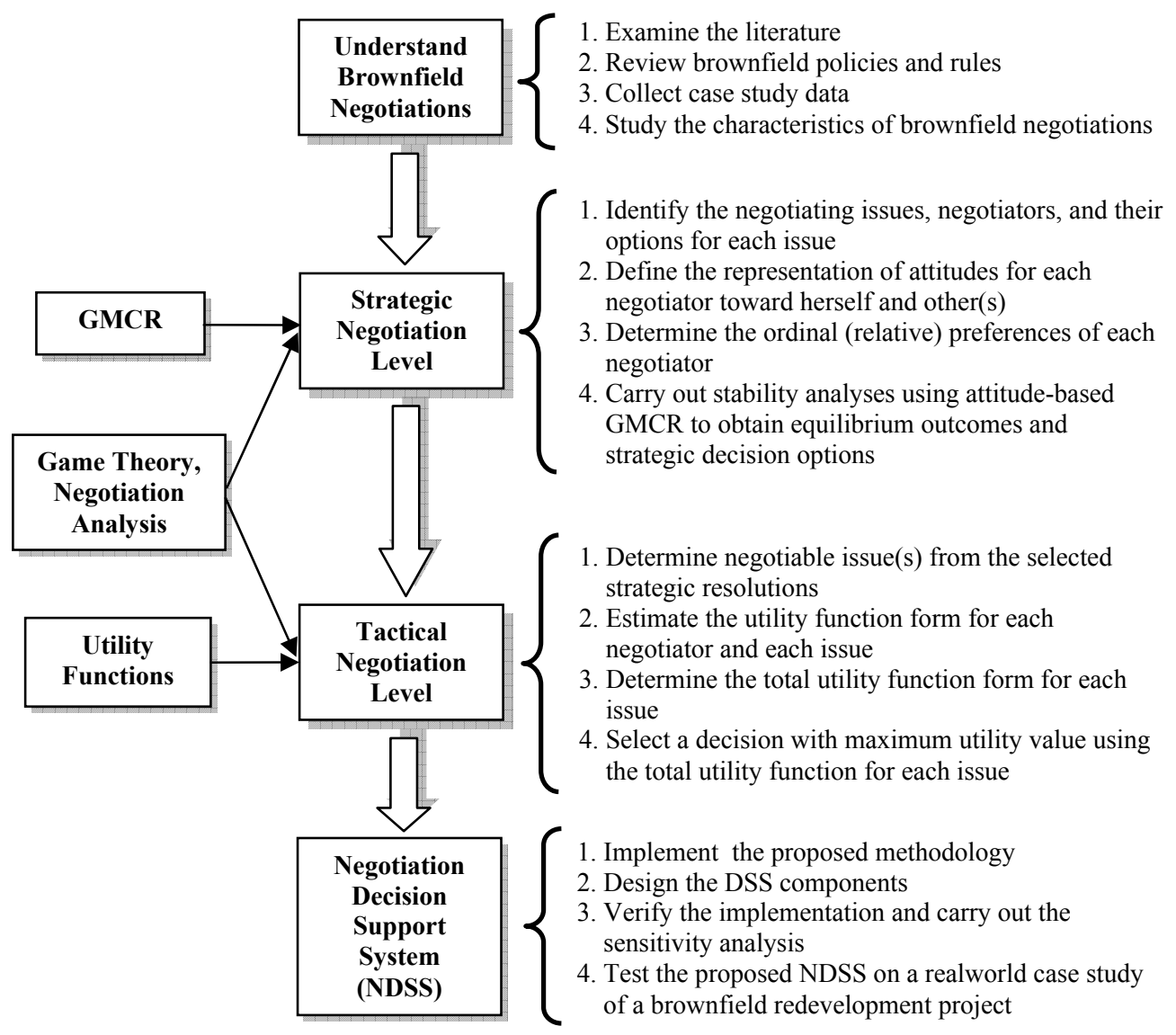

Figure 5 - Proposed Negotiation Framework.

According to the above definition, the attitudes of the DMs can be represented in a matrix format, as shown in Table 3 for a conflict having two DMs $i$ and $j$, in which each cell entry can take on a value of ' + ', '0' or '-'. For example, in a negotiation between two DMs (DM 'o': owner; DM ' $\mathrm{g}$ ': government), it is assumed that each DM decides rationally and the attitudes matrix is represented as displayed in Table 4. As can be seen, the owner and the government are positive towards themselves since $\mathrm{e}_{\mathrm{oo}}=+$ and $\mathrm{e}_{\mathrm{gg}}=+$ and neutral towards each other $\left(\mathrm{e}_{\mathrm{og}}=0\right.$ and $\left.\mathrm{e}_{\mathrm{go}}=0\right)$.

Table 3 - Tabular Representation of Attitudes (Inohara et al., 2007).

\begin{tabular}{c|c|c}
\hline DM & i & $j$ \\
\hline $\mathrm{i}$ & $\mathrm{e}_{\mathrm{ii}}$ & $\mathrm{e}_{\mathrm{ij}}$ \\
\hline $\mathrm{j}$ & $\mathrm{e}_{\mathrm{ji}}$ & $\mathrm{e}_{\mathrm{jj}}$ \\
\hline
\end{tabular}

Table 4 - Attitudes of DMs 'o' and 'g' in a Regular Analysis.

\begin{tabular}{c|c|c}
\hline $\mathrm{DM}$ & $\mathrm{o}$ & $\mathrm{g}$ \\
\hline $\mathrm{o}$ & $\mathrm{e}_{\mathrm{oo}}=+$ & $\mathrm{e}_{\mathrm{og}}=0$ \\
\hline $\mathrm{g}$ & $\mathrm{e}_{\mathrm{go}}=0$ & $\mathrm{e}_{\mathrm{gg}}=+$ \\
\hline
\end{tabular}




\subsubsection{Attitude-Based GMCR}

The attitude definition given above is used to define new attitude-based solution concepts (i.e., stability types) within the GMCR framework. More details about attitude-considered solution concepts can be found in Inohara et al. (2008). In order to utilize the attitudeincorporated GMCR, two stages are considered: modeling and analysis, as shown in Figure 4.

In order to carry out the modeling stage, the involved DMs and their available options are first determined. It can be assumed that both DMs participating in this brownfield case study have reviewed the different choices available to them and selected the following options shown in Table 5.

Table 5 - DMs' Options and 12 Feasible States.

\begin{tabular}{|c|c|c|c|c|c|c|c|c|c|c|c|c|c|}
\hline \multirow{2}{*}{ DMs } & \multirow{2}{*}{ Options } & \multicolumn{12}{|c|}{12 Feasible States } \\
\hline & & $\mathbf{0}$ & 1 & 2 & 3 & 4 & 5 & 6 & 7 & 8 & 9 & 10 & 11 \\
\hline \multirow{2}{*}{ Owner } & 1)Accept Liability & $\mathrm{N}$ & $\mathrm{Y}$ & $\mathrm{N}$ & Y & $\mathrm{N}$ & Y & $\mathrm{N}$ & $\mathrm{Y}$ & $\mathrm{N}$ & $\mathrm{Y}$ & $\mathrm{N}$ & $\mathrm{Y}$ \\
\hline & 2) Sell Property & $\mathrm{N}$ & $\mathrm{N}$ & Y & $\mathrm{Y}$ & $\mathrm{N}$ & $\mathrm{N}$ & $\mathrm{Y}$ & $\mathrm{Y}$ & $\mathrm{N}$ & $\mathrm{N}$ & $\mathrm{Y}$ & Y \\
\hline \multirow{2}{*}{ Government } & 3) Share Costs & $\mathrm{N}$ & $\mathrm{N}$ & $\mathrm{N}$ & $\mathrm{N}$ & Y & $\mathrm{Y}$ & $\mathrm{Y}$ & Y & $\mathrm{N}$ & $\mathrm{N}$ & $\mathrm{N}$ & $\mathrm{N}$ \\
\hline & 4) Lawsuit & $\mathrm{N}$ & $\mathrm{N}$ & $\mathrm{N}$ & $\mathrm{N}$ & $\mathrm{N}$ & $\mathrm{N}$ & $\mathrm{N}$ & $\mathrm{N}$ & Y & Y & $\mathrm{Y}$ & $\mathrm{Y}$ \\
\hline
\end{tabular}

As shown in Table 5, a state is a combination of available options and represents a possible solution for the conflict. Each feasible state is assigned a number label for referencing purposes. In a given column, a "Y" means "yes", the option opposite the $\mathrm{Y}$ is selected by the DM controlling it, whereas an "N" indicates "no", it is not taken. For example, state 2 in Table 5 represents the scenario in which the owner does not accept liability, as indicated by the $\mathrm{N}$, but sells the property, as indicated by the Y. State 2 also indicates that the government does not share the costs, as indicated by the $\mathrm{N}$ beside option 3, and does not file the case in court, as marked by the $\mathrm{N}$ beside option 4 .

The most preferred state for the owner is state 4 and for the government state 1 . The least preferred state for the owner is state 9 and for the government state 4 . The remaining states are placed between the most and least preferred states with respect to each DM. In order to develop the Graph Model representation for the case study, a reachable list is first defined. The reachable list for each DM for a specified state is the set of states that can be reached when the particular DM changes his or her strategy, while the strategies of all the other DMs remain fixed. The reachable lists for the case study are shown in Figure 6. In addition, a graph is provided to display the states that the owner can reach in one step from states $0,1,2$, and 3 . The circles represent the states and the arrows depict the moves among the states. 


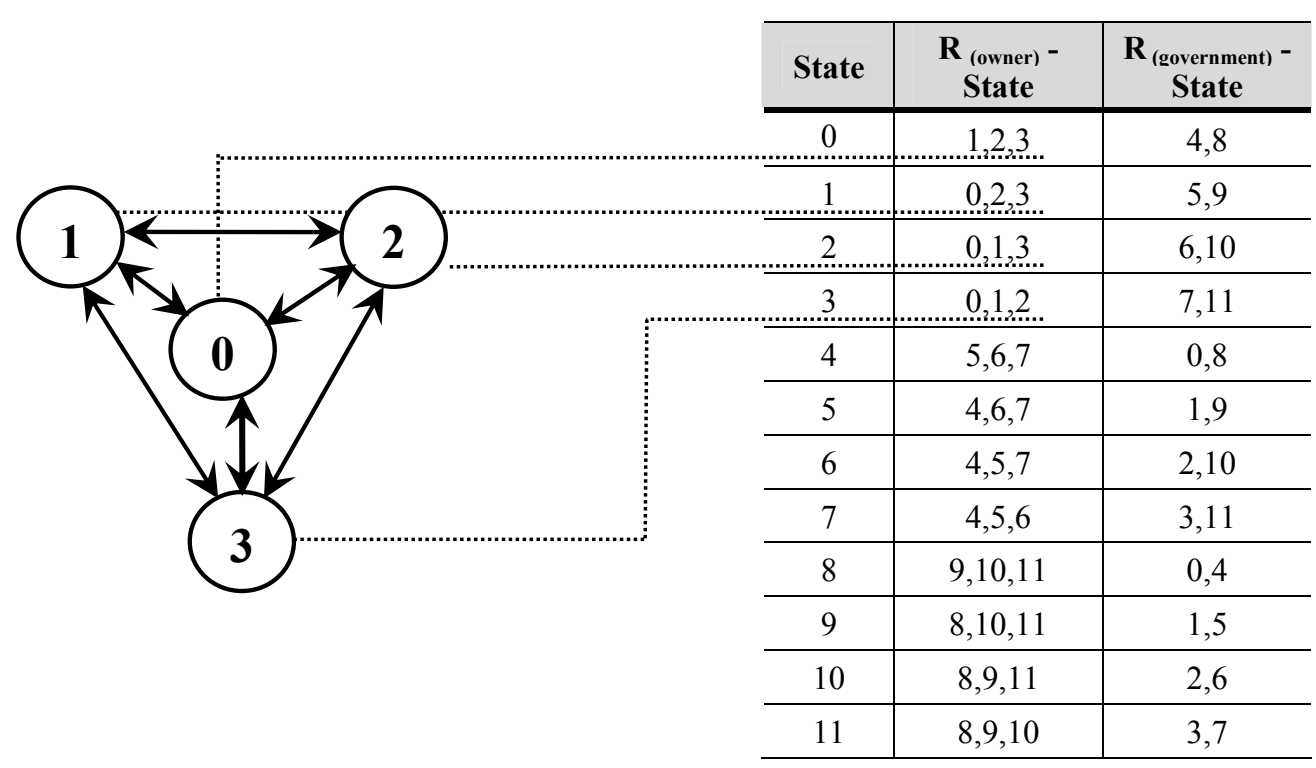

Figure 6 - Reachable Lists and the Owner's Graph Model for States 0, 1, 2, and 3.

A stability analysis is the systematic study of potential moves and countermoves by the DMs as they jostle for more preferred positions during the evolution of the conflict. A stability analysis which takes attitudes into account can be carried out at the stability analysis stage, as shown in Figure 4. The solution concepts, defined in Table 2, and the attitude matrix, such as in Table 4, are used to determine if each of the feasible states is stable for each of the DMs according to each of the solution concepts. If a state possesses some type of stability for all DMs, it is called an equilibrium state, and this state constitutes a possible resolution to the conflict (Fraser \& Hipel, 1984). All other states are unstable for at least one of the DMs and, therefore, are not considered as possible resolutions.

In order to assess the influence of the DMs' attitudes on the outcomes of the negotiations, three attitude scenarios are considered, as shown in Figure 7. With respect to each attitude matrix, an attitude-based stability analysis is carried out and a set of equilibrium states or possible resolutions of the conflict is found. As indicated in Figure 7, for three attitude scenarios, three sets of outcomes are determined, and the resulting outcomes are then discussed below. It should be mentioned that more discussions about this brownfield case study are provided by Yousefi et al. $(2008,2010)$. 


\begin{tabular}{|c|c|c|c|}
\hline \multirow{4}{*}{ Neutral } & \multicolumn{3}{|c|}{ Attitude Matrix } \\
\hline & DMs & 0 & G \\
\hline & 0 & + & 0 \\
\hline & G & 0 & + \\
\hline \multirow{4}{*}{ Negative } & DMs & o & $c$ \\
\hline & 0 & + & - \\
\hline & G & _- & + \\
\hline & DMs & 0 & G \\
\hline \multirow[t]{2}{*}{ Positive } & 0 & + & + \\
\hline & G & + & + \\
\hline
\end{tabular}
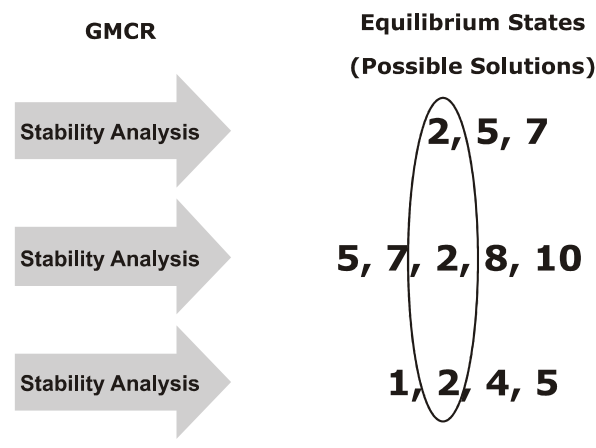

Figure 7 - The Resulting Strategic Solutions for the Brownfield Case Study.

\subsubsection{Discussion of the Resulting Strategic Decisions}

As shown in Figure 7, the DMs had initially neutral (zero) attitudes toward each other, then they had negative attitudes towards each other, and finally, they had positive attitudes toward each other. The objective is to examine how changes in the DMs' attitudes in this case study can influence the outcome of their negotiation. Considering the results of the three scenarios shown in Figure 7, the following observations are made:

1. The increase in the number of solution options (equilibria) in a conflict may help the involved DMs to choose a better possible solution from the resulting equilibrium states;

2. Equilibrium states 2,4 , and 5 are more preferred for both DMs than the equilibrium states 8 and 10 obtained from the middle scenario in Figure 7. In other words, the positive attitudes of the DMs towards themselves and each other can mitigate the degree of hostility involved in outcomes 8 and 10; and

3. One important observation is that the resulting equilibria for the three scenarios share equilibria 2 and 5, as shown in the right column in Figure 7. Solution options 2 and 5 are the only common equilibria with respect to the three different DMs' attitudes reflected in the three attitude scenarios. In other words, equilibrium states 2 and 5 have demonstrated stability and no matter how the DMs' attitudes change in the three scenarios, the two equilibrium states have resulted as a possible solution for the conflict. Thus, the DMs may consider each of these equilibria as a reasonable decision and a strategic outcome of their conflict and may cooperatively continue their interactive negotiation to develop a detailed level of tradeoffs for the conflicting issues involved in solutions 2 and 5. It should be noted that the only issue in solution 2 is that the owner sells the property, as indicated by "Y" in Table 5 . The issues indicated by "N" for that equilibrium are not considered to be conflicting issues. For example, outcome 5 consists of two conflicting issues indicated by the two Ys in this outcome: the amount of liability that the owner accepts and the amount of cost that the government shares. From the two possible solutions 2 and 5, the owner and the government can strategically agree on outcome 2 , which has only one conflicting issue, and continue to further negotiate detailed trade-offs in order to arrive at an agreed upon solution with respect to the selling price of the owner's property. Such negotiations have to be carried out at the tactical level rather than at the strategic decision-making level. 


\subsection{Tactical Level of Negotiation}

The strategic decision state from the above strategic study can be further negotiated by the involved DMs at the tactical (detailed) level. The tactical level of the negotiation methodology complements the strategic level developed in the previous section. Although it is crucial for the DMs to agree on a strategic decision, it is not the final solution of the conflict. The strategic solution only identifies a DM's best course of action and advises the DM which actions are in a particular DM's best interests and which responses would be in the interests of the other DM. The strategic solution does not provide further detailed information (e.g., the specific amount of the redevelopment costs a DM must pay) about using the obtained strategic solution to reach a detailed stable agreement. Therefore, a tactical negotiation approach is needed to complement the strategic negotiation with the goal of specifying the exact amount of compromise needed to reach a mutually acceptable detailed solution. Therefore, the objective of this subsection is to present a negotiation methodology at the tactical level using the concept of utility theory. As discussed in Subsection 5.2, the involved DMs in the brownfield case study mutually agreed upon outcome 2 as the most beneficial solution at the strategic level of negotiation. The DMs also agreed to further negotiate the conflicting issues within the strategic solution (i.e., state 2). The only conflicting issue within state 2 is the selling price of the owner's property. Therefore, in this case study, it is assumed that the owner intends to sell the contaminated property to the government to avoid brownfield liabilities, and the government wants to purchase the property in order to clean up the land quickly. The following tactical negotiation methodology presents the exact amount of concession needed to reach agreement at the detailed level. The methodology development is proposed in the following two steps.

\subsubsection{Step 1: Determine Utility Function Form for the Decision Makers}

Utility analysis explains the relative satisfaction from the results of decision making. If a DM has to rank the consequences in order of his preferences, it is convenient to represent preferences with a utility function and reason indirectly about the preferences by means of these utility functions. Utility function forms represent and describe, for each DM, the tradeoffs between different consequences (Keeney \& Raiffa, 1976). If an appropriate utility is assigned to each possible consequence and the expected utility of each alternative is calculated, then the best course of action is the alternative with the highest expected utility (Kilgour, 2006). In other words, when cardinal utility analysis is used, DMs try to maximize their own expected utility, and if they cooperatively negotiate, they strive to maximize their joint expected utility value.

Among many types of utility function suggested, polynomial utility functions are more flexible for assigning risk attitudes (either risk aversion or risk preference) to DMs (Zuhair et al., 1992; Pena-Mora \& Wang, 1998). Accordingly, in this research, reformatted polynomial utility functions are assigned to the DMs involved in this brownfield case study, as shown in Figure 8. The term " $n$ " in the functions of the DMs shown in Figure 8 is the power of the polynomial function and can change the shape of the functions. The power term (n) also represents the DMs' attitude in the following three ranges:

1. When $0 \leq \mathrm{n}<1$, then the polynomial utility function has a convex shape, which indicates that the DM has a negative attitude towards the other DM. The closer the "n" value is to zero, the less cooperative the DM intends to be in interactive negotiation.

Pesquisa Operacional, v.30, n.2, p.281-304, Maio a Agosto de 2010 
2. When $1<\mathrm{n} \leq 10$, then the polynomial utility function has a concave shape, which indicates that the DM has a positive attitude towards the other DM. The closer the "n" value is to 10 , the more cooperative the DM intends to be in the negotiation.

3. When $\mathrm{n}=1$, then the polynomial utility function is linear, which indicates that the DM intends to have a neutral attitude towards the other DM.
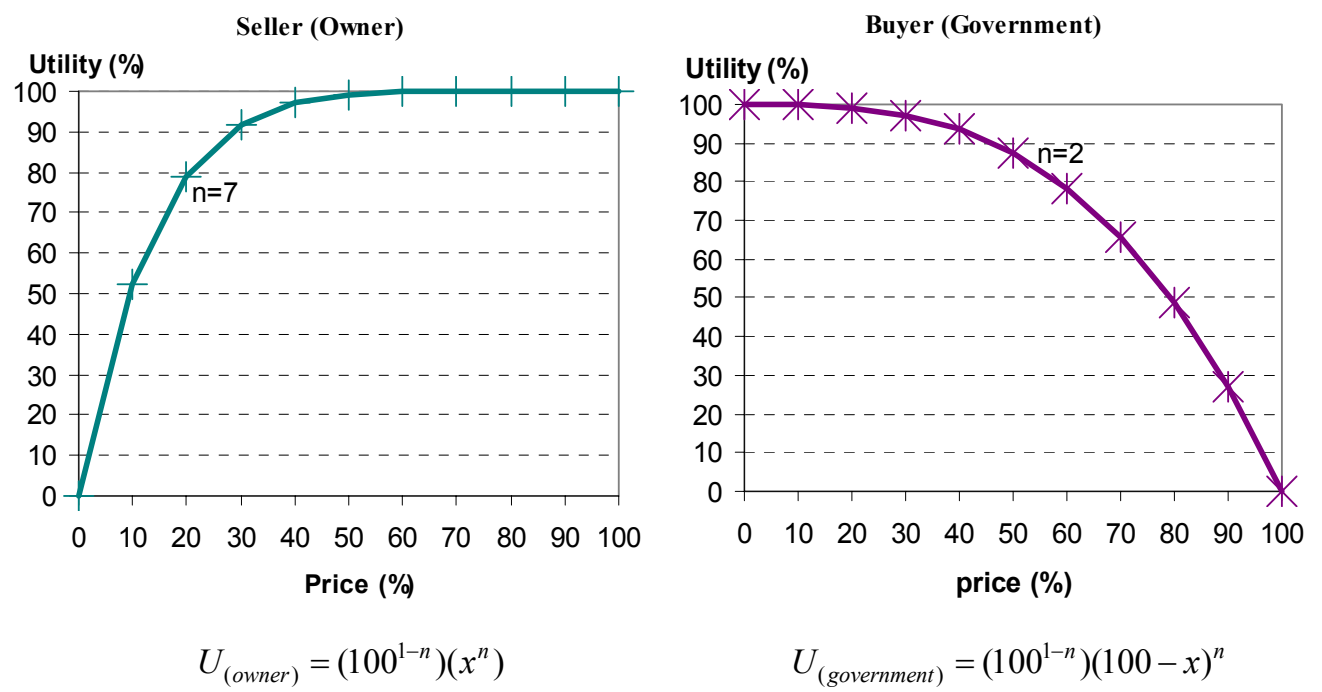

Figure 8 - DMs' Utility Function Forms for the Property's Price.

According to the above discussion and as shown in Figure 8, with respect to the tactical negotiation between the two DMs in this case study, the owner tries to be more cooperative and gets rid of the contaminated land by selling it to the government. Therefore, " $n=7$ " is selected for the owner's utility function. On the other hand, the government knows that there are uncertainties involved in buying the contaminated land. However, although the government has agreed to buy the property, it is less cooperative than the owner and, as such, " $n=2$ " is selected for the government's utility function.

\subsubsection{Step 2: Obtain Settlement Point Using an Integrated Utility Function}

Once the two DMs' utility function forms are selected, the interactive negotiation process between the owner and the government can be modeled. As shown in Figure 9, the utility functions of the owner and the government are summed to obtain a new integrated function of the DMs for the conflicting issue (the selling price of the owner's property) (Ji et al., 2007). By summing the utility function of the DMs, an integrated utility function for the negotiating issue is obtained, as shown in Figure 9. The integrated utility function is simply the summation of the utility values associated with the two individual functions. For point $\mathrm{H}$ in Figure 9, for example, the total utility function is obtained by algebraically calculating the length of line $\mathrm{DH}=\mathrm{DE}+\mathrm{DF}$. The same approach is applied to other points on the integrated utility function. 
The maximum point on the integrated utility function represents the maximum utility value and, as such, the maximum level of satisfaction for DMs (Kilgour, 2006; Darling \& Mumpower, 1990). Accordingly, the maximum point on the integrated utility function is point B with the maximum combined utility value. As shown in Figure 9, point B represents the settlement point or the point of detailed agreement because both DMs have reached the highest degree of satisfaction for their cooperative effort (Kilgour, 2006). The settlement point is used to obtain the percentage of price (indicated on the horizontal axis) that the government should pay to the owner. In Figure 9, point $\mathrm{N}$ indicates $30 \%$ of the price is paid by the government. In other words, if the initial price of the owner's property is $\$ 200,000$, for example, the government should pay $\$ 60,000(0.3 \times \$ 200,000)$ to the owner for its contaminated property. As a result of mutually agreed upon tactical negotiation in this case study, the owner receives $\$ 60,000$ and avoids brownfield remediation liability and the government purchases the brownfield property for a reasonable price in order to restore the property for the benefit of society.

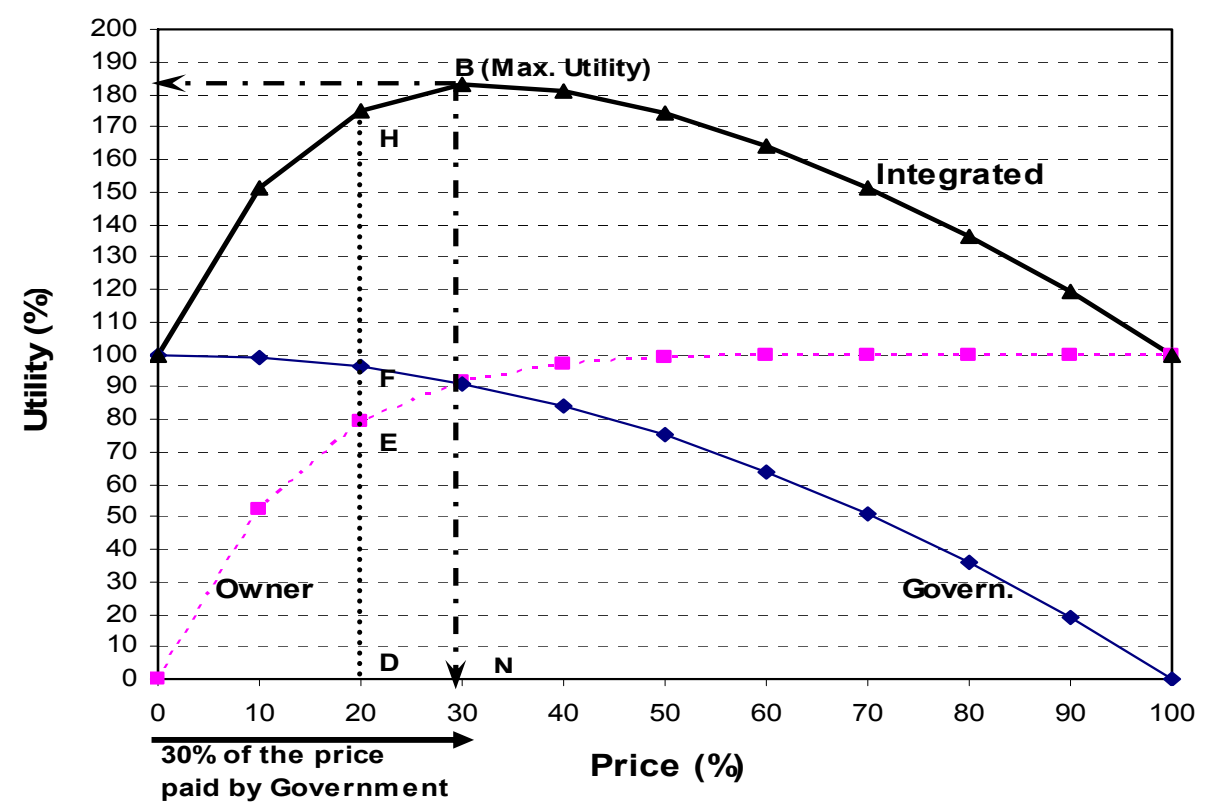

Figure 9 - Tactical Negotiation Results.

\section{Conclusions}

The extreme monetary costs of brownfield projects often stall the initiation of projects. Moreover, brownfield projects involve several uncertainties that seriously contribute to the challenges of brownfield redevelopment, such as uncertainty about the extent of the contamination and the uncertainty in cleanup costs. The growing uncertainties and huge costs of brownfield redevelopment often lead to serious conflicts arising among the involved participants. Because brownfield redevelopment can be considered as an important component of infrastructure revival, the foregoing types of soft OR (operation research) tools should have widespread applicability. 
As a soft systems thinking approach, a systematic negotiation framework that takes into account the negotiators' attitudes was proposed to overcome and resolve the challenging disputes among the participants involved in brownfield redevelopment. The proposed negotiation methodology consists of two complementary levels of negotiation: strategic and tactical. At the strategic level, the proposed methodology employs the Graph Model to determine the most likely compromise resolution. At the tactical level, the conflicting issues within the strategic solution are first highlighted. Then the proposed methodology uses utility theory to arrive at the exact amount of concession needed to reach a detailed agreement over the conflicting issues. Also, the proposed negotiation methodology can be conveniently implemented as a negotiation decision support system (NDSS). Such a computer-based system has great advantages with respect to speed, accuracy, practicality, flexibility, reliability, and versatility.

The proposed research introduces new soft systems engineering methodologies to examine the influence of DMs' attitudes on the outcome of brownfield negotiations. Moreover, the system helps decision makers tackle various real-world controversies, particularly in brownfield reconstruction projects. Finally, the research is expected to help improve negotiation methodologies for resolving challenging brownfield disputes existing around the globe in both industrialized and developing nations.

\section{References}

(1) Al-Mutairi, M.S.; Hipel, K.W. \& Kamel, M.S. (2008). Fuzzy Preferences in Conflicts. Journal of Systems and Systems Engineering, 17(3), 257-276.

(2) Barnett, J. (1995). The Fractured Metropolis-Improving the New City, Restoring the Old City, Reshaping the Region. Harper Collins, New York, USA.

(3) Bartsch, C.; Andress, C.; Seitzman, J. \& Cooney, D. (1991). New Life for Old Buildings: Confronting Environmental and Economic Barriers to Industrial Reuse. Northeast-Midwest Institute, Washington, USA.

(4) Begley, R. (1997). Resurrecting Brownfields. Environmental Science and Technology, 31(5), 226A- 230A.

(5) Benazon, N. (1995). Soil Remediation: A Practical Overview of Canadian Cleanup Strategies and Commercially Available Technology. Hazardous Materials Management (Fall), 10-26.

(6) Ben-Haim, Y. \& Hipel, K.W. (2002). The Graph Model for Conflict Resolution with Information-gap Uncertainty in Preferences. Applied Mathematics and Computation, 126, 319-340.

(7) Bourne, L.S. (1995). Reurbanization and Urban Land Development: US Cities in Comparative Context. Office of Technology Assessment, Congress of the United States, Washington.

(8) Checkland, P. (1999). Soft Systems Methodology: A 30-year Retrospective and Systems Thinking, Systems Practice. 2nd ed., Wiley, Chichester, Sussex, United Kingdom.

(9) Cheung, S. \& Suen, H.C.H. (2002). A Multi-attribute Utility Model for Dispute Resolution Strategy Selection. Construction Management and Economics, 20, 557-568. 
(10) Cohen, S. (2002). Negotiating Skills for Managers. McGraw-Hill, New York, USA.

(11) Darling, T. \& Mumpower, J.L. (1990). Modeling Cognitive Influences on the Dynamics of Negotiations. Proc., 23rd Annu. International Conf on Sys. Sci., IEEE Computer Society Press, 22-30.

(12) De Sousa, C. (2001). Contaminated Sites: The Canadian Situation in an International Context. Journal of Environmental Management, 62, 131-154.

(13) Eden, C. (1988). Cognitive Mapping: A Review. European Journal of Operational Research, 36, 1-13.

(14) Fang, L.; Hipel, K.W. \& Kilgour, D.M. (1993). Interactive Decision Making: The Graph Model for Conflict Resolution. Wiley, New York, USA.

(15) Fang, L.; Hipel, K.W.; Kilgour, M. \& Peng, X. (2003a). A Decision Support System for Interactive Decision Making, Part 1: Model Formulation. IEEE Transactions on Systems, Man and Cybernetics, Part C, 33(1), 42-55.

(16) Fang, L.; Hipel, K.W.; Kilgour, M. \& Peng, X. (2003b). A Decision Support System for Interactive Decision Making, Part 2: Analysis and Output Interpretation. IEEE Transactions on Systems, Man and Cybernetics, Part C, 33(1), 56-66.

(17) Fraser, N.M. \& Hipel, K.W. (1984). Conflict Analysis: Models and Resolutions. North Holland, New York, USA.

(18) Friend, J.K. \& Hickling, A. (2005). Planning Under Pressure: The Strategic Choice Approach. Butterworth-Heineman, Oxford, The UK.

(19) Glasner, K. (2000). Contract Disputes, the Role of ADR. Dispute Resolution Journal, 55(3), 50-55.

(20) Griffiths, L. (1996). Contaminated Property in Canada. Carswell, Thomson Professional Publishing, Toronto, Canada.

(21) Hamouda, L.; Kilgour, D.M. \& Hipel, K.W. (2004). Strength of Preference in the Graph Model for Conflict Resolution. Group Decision and Negotiation, 13(5), 449-462.

(22) Hamouda, L.; Kilgour, D.M. \& Hipel, K.W. (2006). Strength of Preference in Graph Models for Multiple Decision Maker Conflicts. Applied Mathematics and Computation, 179, 314-327.

(23) Harmon, K.M.J. (2003). Resolution of Construction Disputes: A Review of Current Methodologies. Leadership Management Engineering, 3(4), 187-201.

(24) Henderson, D.A. (1996). Mediation Success: An Empirical Analysis. Ohio St. J. On Dispute Resolution, 105.

(25) Hipel, K.W. (Editor). (2009a). Conflict Resolution, Volume 1. Eolss Publishers, Oxford, United Kingdom (ISBN-978-1-84826-120-4 (Adobe e-Book), ISBN-978-1-84826-570-7, Library Edition (Hard Copy).

(26) Hipel, K.W. (Editor). (2009b). Conflict Resolution, Volume 2. Eolss Publishers, Oxford, United Kingdom (ISBN-978-1-84826-121-1 (Adobe e-Book), ISBN-978-1-84826-571-4, Library Edition (Hard Copy). 
(27) Hipel, K.W. \& Ben-Haim, Y. (1999). Decision Making in an Uncertain World: Information-gap Modeling in Water Resources Management. IEEE Transactions on Systems, Man and Cybernetics, Part C, 29(4), 506-517.

(28) Hipel, K.W. \& Fang, L. (2005). Multiple Participant Decision Making in Societal and Technological Systems. In: Systems and Human Science - For Safety, Security, and Dependability: Selected Papers of the 1st International Symposium [edited by T. Arai, S. Yamamoto and K. Makino], SSR2003, Osaka, Japan, published by Elsevier, Amsterdam, The Netherlands, Chapter 1, 3-31.

(29) Hipel, K.W.; Jamshidi, M.M.; Tien, J.M. \& White, C.C. (2007). The Future of Systems, Man, and Cybernetics: Application Domains and Research Methods. IEEE Transactions on Systems, Man, and Cybernetics, Part C: Applications and Reviews, 37(5), 726-743.

(30) Hipel, K.W.; Kilgour, D.M.; Fang, L. \& Peng, X. (2001). Strategic Support for the Services Industry. IEEE Transactions on Engineering Management, 48(3), 358-369.

(31) Howard, N. (1971). Paradoxes of Rationality: Theory of Metagames and Political Behavior. MIT Press, Cambridge, Massachusetts, USA.

(32) Inohara, T. \& Hipel, K.W. (2008a). Coalition Analysis in the Graph Model for Conflict Resolution. Accepted for publication, Systems Engineering, 11(4), 343-359.

(33) Inohara, T. \& Hipel, K.W. (2008b). Interrelationships Among Noncooperative and Coalition Stability Concepts. Journal of Systems Science and Systems Engineering, 17, 1-29.

(34) Inohara, T.; Hipel, K.W. \& Walker, S. (2007). Conflict Analysis Approaches for Investigating Attitudes and Misperceptions in the War of 1812. Journal of Systems Science and Systems Engineering, 16(2), 1-21.

(35) Inohara, T.; Yousefi, S. \& Hipel, K.W. (2008). Propositions on Interrelationships among Attitude-based Stability Concepts. Proceedings of the 2008 IEEE International Conference on Systems, Man, and Cybernetics, held in Singapore, October 12-15, 2502-2507.

(36) Ji, S.; Liang, Y.; Xiao, X.; Li, J. \& Tian, Q. (2007). An Attitude-adaptation Negotiation Strategy in Electronic Market Environments. Eight ACIS International Conference on Software Engineering, Artificial Intelligence, Networking, and Parallel/Distributed Computing, IEEE Computer Society, 125-130.

(37) Kahneman, D. \& Tversky, A. (2000). Choices, Values, and Frames. Cambridge University Press, Cambridge.

(38) Keeney, R.L. \& Raiffa, H. (1976). Decisions with Multiple Objectives: Preferences and Value Tradeoffs. Wiley, New York, USA.

(39) Kilgour, D.M. (2006). Introduction to Game Theory, MA 235 Course Package. Wilfrid Laurier University Press, Waterloo, Canada.

(40) Kilgour, D.M.; Hipel, K.W.; Fang, L. \& Peng, X. (2001). Coalition Analysis in Group Decision and Support. Group Decision and Negotiation, 10(2), 159-175.

(41) Li, K.W.; Hipel, K.W.; Kilgour, D.M. \& Fang, L. (2004a). Preference Uncertainty in the Graph Model for Conflict Resolution. IEEE Transactions on Systems, Man, and Cybernetics, Part A, 34(4), 507-520. 
(42) Li, K.W.; Kilgour, D.M. \& Hipel, K.W. (2004b). Status Quo Analysis of the Flathead River Conflict. Water Resources Research, 40(5), W05S03, doi:10.1029/2003WR002596 (9 pages).

(43) Li, K.W.; Kilgour, D.M. \& Hipel, K.W. (2005). Status Quo Analysis in the Graph Model for Conflict Resolution. Journal of the Operational Research Society, 56, 699-707.

(44) Loosemore, M. (1999). Bargaining Tactics in Construction Disputes. Construction Management and Economics, 17, 177-188.

(45) Mix, D. (1997). ADR in the Construction Industry: Continuing the Development of a More Efficient Dispute Resolution Mechanism. 12 Ohio St. J. On Dispute Resolution, 463.

(46) Nash, J.F. (1950). Equilibrium Points in n-Person Games. Proceedings of National Academy of Sciences, 36, 48-49.

(47) Nash, J.F. (1951). Noncooperative Games. Annals of Mathematics, 54(2), 286-295.

(48) National Round Table on the Environment and the Economy (NRTEE) (2003). Cleaning up the Past, Building the Future: A National Brownfield Redevelopment Strategy for Canada. ISBN 1-894737-05-9, Ottawa, Canada.

(49) Obeidi, A.; Hipel, K.W. \& Kilgour, D.M. (2005). The Role of Emotions in Envisioning Outcomes in Conflict Analysis. Group Decision and Negotiation, 14, 481-500.

(50) Obeidi, A.; Kilgour, D.M. \& Hipel, K.W. (2009). Perceptual Stability Analysis of a Graph Model System. IEEE Transaction on Systems, Man and Cybernetics, Part A, Humans and Systems, 39(5), 993-1006.

(51) Page, W. (1997). Contaminated Sites and Environmental Cleanup: International Approaches to Presentation, Remediation, and Reuse. Academic Press, San Diego, USA.

(52) Pena-Mora, F. \& Wang, C.Y. (1998). Computer-Supported Collaborative Negotiation Methodology. Journal of Computing in Civil Engineering, 12(2), 64-81.

(53) Pinnell, S. (1999). Partnering and the Management of Construction Disputes. Dispute Resolution Journal, 54(1), 16-22.

(54) PolicyLink (2008). Equitable Development Toolkit. Building Regional Equity. $<$ http://www.policylink.org/EDTK/Brownfields/default.html $>$, accessed on January 05, 2009.

(55) Raiffa, H.; Richardson, J. \& Metcalfe, D. (2002). Negotiation Analysis: The Science and Art of Collaborative Decision Making. The Belknap Press of Harvard University Press, Cambridge, USA.

(56) Richter, I.E. (2000). The Project Neutral: Neutralizing Risk, Maintaining Relationships \& Watching the Bottom Line. Construction Business Review, 8(2), 52-54.

(57) Rosenhead, J. \& Mingers, J. (Ed.) (2001). Rational Analysis for a Problematic World Revisited, Problem Structuring Methods for Complexity, Uncertainty and Conflict. John Wiley \& Sons, Ltd., Chichester, xviii + 366 pages. 
(58) US Department of Housing and Urban Development. (2007). Annual Report. $<$ http://www.hud.gov/offices/adm/foia/foia2007annualreport.doc $>$, accessed on March 23, 2008 .

(59) Von Neumann, J. \& Morgenstern, O. (1944). Theory of Games and Economic Behaviour. 1st ed. Wiley, New York, USA.

(60) Walker, S.; Hipel, K.W. \& Inohara, T. (2009). Strategic Decision Making for Improved Environmental Security: Coalitions and Attitudes. Journal of Systems Science and Systems Engineering, 18(4), 461-476.

(61) Xu, H.; Hipel, K.W. \& Kilgour, D.M. (2009a). Multiple Levels of Preference in Interactive Strategic Decisions. Discrete Applied Mathematics, 57, 3300-3313.

(62) Xu, H.; Hipel, K.W. \& Kilgour, D.M. (2009b). Matrix Representation of Solution Concepts in Multiple Decision Maker Graph Models. IEEE Transactions on Systems, Man and Cybernetics, Part A, 39(1), 96-108.

(63) Yousefi, S.; Hipel, K.W. \& Hegazy, T. (2008). Construction Negotiations: Does Attitude Matter? Proceedings of the Canadian Society for Civil Engineering, the 2008 Annual Conference, held in Quebec City, Canada, June 10-13, 2008, pp. 289-297.

(64) Yousefi, S. Hipel, K.W. \& Hegazy, T. (2010). Considering Attitudes in Strategic Negotiation over Brownfield Disputes. ASCE Journal of Legal Affairs and Dispute Resolution in Engineering and Construction, to appear.

(65) Zuhair, S.M.M.; Taylor, D.B. \& Kramer, R.A. (1992). Choice of Utility Function Form: Its Effect on Classification of Risk Preferences and the Prediction of Farmer Decisions. Agricultural Economics, 6, 333-344. 